\title{
Pengembangan Kawasan Riverfront di Sungai Banjir Kanal Timur Kota Semarang dengan Konsep Eco-Riverwalk Village (Studi Kasus : Kelurahan Mlatiharjo, Kecamatan Semarang Timur)
}

\author{
The Development of Banjir Kanal Timur Riverfront Settlement on The \\ Concept of Eco-Riverwalk Village (Case Study: Kelurahan Mlatiharjo, \\ Kecamatan Semarang Timur)
}

\author{
M.H. Subianto, P. Prayogo, R.D. Gustina, A. Syahrani, D.A. Sihaloho, R. Nurrokhmi, \\ R.J. Royson, T.R. Debby, L. Haulah, D.O. Hapsari, R. Syahlisben* \\ ${ }^{a}$ Departemen Perencanaan Wilayah dan Kota Universitas Diponegoro, Semarang, Indonesia
}

\begin{abstract}
Abstrak
Kota Semarang memiliki dua kanal yang dibangun dengan tujuan sebagai pengendali banjir yang kerap menjadi permasalahan kota dari abad ke 19, Banjir Kanal Timur (BKT) dan Banjir Kanal Barat (BKB). Pembuatan kanal yang merupakan terusan dari Sungai Garang ini berperan sebagai drainase primer yang diarahkan langsung ke arah laut. Lemahnya penerapan peraturan terkait pemanfaatan kawasan tepi sungai mendorong banyaknya pelanggaran oleh masyarakat sekitar seperti banyaknya bangunan di sepanjang tepi sungai BKT. Terdapatnya bangunan yang dimanfaatkan sebagai tempat tinggal maupun berdagang ini mendorong pembuangan limbah domestik secara langsung ke sungai. Hal ini menjadi faktor pendorong terjadinya banjir disamping terdapatnya permasalahan akibat alam seperti erosi. Kedua masalah tersebut menyebabkan pendangakalan di hilir sungai dan mendorong terjadinya luapan air sungai ke kawasan perumahan sekitar. Pembangunan dengan konsep Eco-Riverwalk Village ini dilakukan sebagai upaya perbaikan ekologi kawasan tepi sungai dengan menjadikan taman linier sebagai identitas baru kawasan tepi sungai di Kelurahan Mlatiharjo. Taman linier merupakan implementasi untuk mewujudkan konsep 'riverwalk' (i.e. kawasan yang walkable di sepanjang sungai) dan meningkatkan nilai estetika kawasan tepi sungai di lokasi perancangan.
\end{abstract}

Kata kunci: BKT; Riverfront; Riverwalk; Taman Linier

\begin{abstract}
Semarang city has two canals which was developed to decrease the flood risk happened since 19th century, those are known as Banjir Kanal Timur (BKT) and Banjir Kanal Barat (BKB). Both canals which are made connected to Sungai Garang are served as primary drainages that flow directly to the sea. The weak regulation of limitation zone (e.g. riverfront) caused many violations done by people around the area by built houses or places for working along BKT riverfront. Many buildings are made as houses (i.e. commonly used by the poor) drives domestic waste dumped in the river. This is one of many driving forces caused flooding in Semarang City (i.e. the nature factor is erosion happen in BKT river upstream). Those problems caused sedimentation in BKT downstream and indirectly caused the water spilled to the settlement around the river. The development by Eco-Riverwalk Village Concept are implemanted as an effort to improve the ecology aspect in riverfront area by build a linear park as a new identity of Kelurahan Mlatiharjo Riverfront. Linear park is the implemantation of 'riverwalk' concept (i.e. the walkable zone along the river) and improve the aesthetic value in case study area.
\end{abstract}

Keyword: BKT; Riverfront; Riverwalk; Linear Park

\footnotetext{
* Corresponding author. Author's Name.

E-mail address: lab.rancang@pwk.undip.ac.id.
} 


\section{Pendahuluan}

Kota Semarang berlokasi di pesisir utara Pulau Jawa dan berbatasan langsung dengan Laut Jawa di sisi utara. Kondisi geografis yang seperti ini menyebabkan kota Semarang memiliki kaitan yang erat dengan wilayah perairan. Sebagai kota pesisir pantai membuat Semarang memiliki banyak daerah yang berbatasan langsung dengan perairan. Kawasan yang berbatasan langsung dengan perairan disebut juga dengan kawasan waterfront. Meskipun kawasan waterfront memiliki banyak potensi dan peluang, kawasan waterfront Kota Semarang justru menerima sejumlah masalah dan ancaman berupa banjir di kawasan tersebut.

Permasalahan banjir merupakan fenomena yang sudah dihadapi sejak abad ke-19, saat Pemerintah Kolonial Belanda membangun Banjir Kanal Barat (BKB) dan Banjir Kanal Timur (BKT) (Suripin, 2004). Penelitian terdahulu menyimpulkan bahwa terdapat tiga jenis banjir di Kota Semarang, yaitu Banjir Lokal, Banjir Pasang dan Banjir Limpasan Sungai (Marfai, 2004). Permasalahan dan ancaman tersebut disebabkan buruknya pengelolaan belum maksimalnya perhatian pemerintah dalammengembangkan kawasan waterfront. Pertumbuhan yang tidak teratur serta kerusakan lingkungan menjadi dampak dari permasalahan tersebut. Oleh karena itu, diterapkan program penanggulangan banjir dengan melakukan kegiatan normalisasi pada sungai Banjir Kanal Barat, yang semula tidak dapat berfungsi sebagaimana mestinya diakibatkan sedimentasi akibat limpasan dari daerah hulu. Pembuatan kanal yang merupakan terusan dari Sungai Garang ini berperan sebagai drainase primer yang diarahkan langsung ke arah laut. Hal tersebut dilakukan untuk menanggulangi permasalahan banjir yang kerap terjadi di Kota Semarang. Namun, sungai pada banjir kanal timur yang saat ini masih belum dilakukan normalisasi, masih memiliki permasalahan seperti banjir yang berdampak pada kerusakan lingkungan.

Lokasi perancangan berada di kawasan pinggir sungai BKT Kota Semarang, tepatnya berada di Kecamatan. Kawasan pinggiran sungai BKT Kota Semarang memang terkenal dengan kawasannya yang rawan banjir (i.e banjir yang kerap terjadi adalah banjir limpasan sungai) permasalahan tersebut menyebabkan dampak permukiman kumuh dan berimbas pada rendahnya kualitas hidup masyarakatnya. Selain itu ditambah lagi dengan terjadinya land subsidence (i.e penurunan muka tanah) di bagian utara atau hilir BKT. Permasalahan tersebut dijabarkan kedalam permasalahan makro, meso dan mikro sebagai berikut:

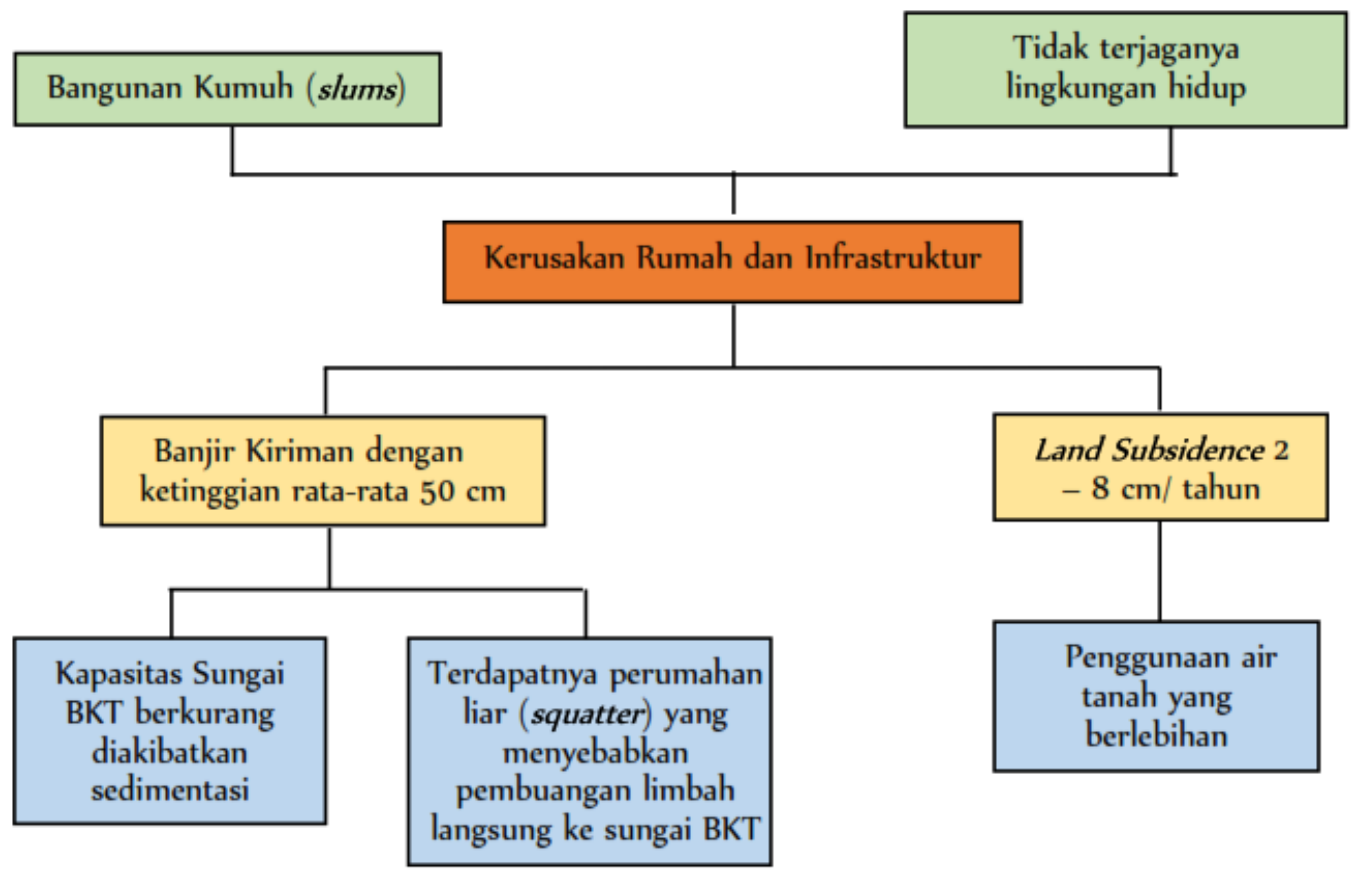

Gambar 1. Pohon Masalah Kawasan Perancangan Mikro (Analisis Penulis, 2017)

Dalam kaitannya dengan wilayah mikro, permasalahan yang ada di sepanjang pinggiran BKT juga merupakan bagian dari permasalahan yang ada di wilayah makro, seperti adanya sedimentasi fluvial yang terendap di dasar sungai BKT. Selain faktor alam, faktor yang disebabkan oleh manusia adalah pembangunan bangunan (i.e. dari hasil observasi ditemukan 
bangunan permanen, semi permanen hingga bangunan nonpermanen). Terdapatnya bangunan liar (i.e. squatter) yang dijadikan lokasi kegiatan perdagangan dan jasa ini menyebabkan pembuangan limbah secara langsung ke sungai BKT. Tidak hanya material berupa tanah yang dibawa oleh erosi di sepanjang sempadan sungai yang dapat mengendap dan menjadi sedimentasi. Limbah domestik (i.e. limbah rumah tangga) dapat mengendap dan menyebabkan pendangkalan di sungai. Sungai BKT yang telah mengalami pendangkalan menyebabkan kapasitas sungai dalam menampung air menjadi berkurang. Dengan kuantitas air yang sama dan kapasitas sungai yang berkurang akibat pendangkalan, air mengalami peluapan ke wilayah studi.

Berbeda dengan permasalahan sebelumnya yang merupakan masalah pada air permukaan (i.e. air sungai). Permasalahan lain yang kerap muncul adalah permasalahan pada penggunaan air tanah yang berlebihan. Kapasitas air tanah yang berkurang menyebabkan lapisan tanah menurun (i.e. disebabkan penopang yang merupakan air tanah telah berkurang). Penurunan muka tanah atau dikenal juga sebagai land subsidence yang terjadi hingga $2-8 \mathrm{~cm}$ per tahun.

Permasalahan seperti banjir dan land subsidence mendorong sebuah permasalahan utama yaitu kerusakan pada lingkungan dan infrastruktur. Rusaknya infrastruktur termasuk diantaranya bangunan berupa rumah. Oleh karena itu, permasalahan yang timbul setelahnya adalah perumahan kumuh (slums) dan tidak terjaganya lingkungan hidup. Hal ini dilihat dari kondisi perumahan yang dilakukan pada observasi lapangan dan tidak terdapatnya RTH maupun tanaman yang tumbuh secara subur.

Melalui permasalahan, potensi dan isu yang terdapat pada kawasan waterfront atau dapat juga dikenal sebagai riverfront (i.e BKT merupakan kawasan riverfront) diterapkan konsep Sustainable Waterfront Settlement di wilayah studi makro dan menerapkan konsep Eco Riverfront di kawasan bantaran BKT yang merupakan konsep meso. Konsep makro diterapkan sebagai upaya dalam meningkatkan ekonomi lokal dengan memanfaatkan sumber daya wilayah studi tanpa merusak ekologi dengan penerapan konsep desain yang tepat. Selain itu, dalam konsep ini pula nilai keadilan (i.e equity) dapat diwujudkan dengan pemerataan akses ke fasilitas atau pelayanan untuk semua masyarakat (terutama masyarakat miskin dan pinggiran), distribusi manfaat pembangunan, dan kesempatan untuk berpartisipasi secara sama dalam proses konsultasi dan pengembangan. Ketiga komponen ini diharapkan dapat mendukung pembangunan fisik dan non-fisik di wilayah studi.

\section{Metode}

Metode analisis dalam penelitian ini menggunakan pendekatan deskriptif analisis. Penelitian deskriptif dilakukan dengan tujuan untuk memberikan gambaran terhadap kondisi eksisting, meliputi potensi dan permasalahan yang ada di Kelurahan Mlatiharjo, Kecamatan Semarang Timur, Kota Semarang. Kemudian teknik analisis data yang terkumpul diolah dan dianalisis dengan deskriptif analitis, yaitu dengan menggambarkan keadaan dari kasus yang diteliti kemudian dianalisis berdasarkan permasalahan-permasalahan yang timbul ditinjau dan dianalisa berdasarkan teori-teori dan peraturan perundang-undangan yang ada sehingga akan menciptakan suatu respon dengan penggunaan data kuantitatif yang digunakan untuk mempertajam analisa kualitatif. Teknik pengumpulan data dilakukan melalui dua sumber, yaitu pengumpulan data primer dan pengumpulan data sekunder. Penggunaan teknik pengumpulan data primer dengan observasi, wawancara, dan penyebaran kuesioner.

Penyebaran kuesioner dan wawancara dilakukan dengan teknik sampling kepada penduduk di Kelurahan Mlatiharjo, Kecamatan Semarang Timur, Kota Semarang. Adapun pengumpulan data sekunder yang dilakukan menggunakan telaah dokumen.

\section{Hasil dan Pembahasan}

\section{Tinjauan Eksisting Lokasi Perancangan}

Wilayah studi yang akan dikaji berada di kelurahan Mlatiharjo Kecamatan Semarang Timur yang berada di Jalan Barito. Luas wilayah yang akan di rancang pada lokasi rancang seluas $25 \mathrm{Ha}$. Lokasi perancangan dekat dengan kawasan industri yakni kawasan industri Terboyo sehingga menjadikannya sebagai lokasi hunian sementara para pekerja atau buruh industri. Oleh karena itu, lokasi perancangan banyak memiliki rumah. Namun lokasi 
perancangan yang berbatasan dengan Banjir Kanal Timur dan sungai Kalibanger menjadikan kawasan tersebut memiliki masalah yaitu banjir dan land subsidence. Selain disebabkan oleh kondisi fisik alam, permasalahan tersebut juga disebabkan karena adanya limpasan air dari sungai Kalibanger setiap kali hujan serta disebabkan oleh daya tampung drainase yang tidak sesuai kapasitasnya. Permasalahan alam tersebut (e.g land subsidence dan banjir) tentu menjadi penghambat dalam pengembangan kawasan permukiman. Padahal, potensi yang dimiliki kawasan perancangan (e.g aksesibilitas menuju kawasan industri dan pusat kota) jika dikembangkan dapat memberi kelebihan bagi lokasi perancangan, sebagai contoh pengembangan kawasan UMKM dengan memadukan daya tarik sungai BKT.

\section{Konsep Desain}

Konsep yang akan diterapkan pada lokasi perancangan yaitu Eco-Riverwalk Village. Istilah Eco (i.e mewakili kata Ekologi) pertama kali diperkenalkan oleh (Haeckel, 1866). Ekologi adalah disiplin ilmu yang mempelajari seluk beluk ekonomi alam. Konsep ekologi kini menjadi kajian mengenai hubungan timbal balik antara makhluk hidup dengan lingkungannya. Sedangkan Riverwalk adalah koridor ruang terbuka untuk pejalan kaki yang menghubungkan beberapa fungsi komersial dan ritel yang ada. Koridor ini terbuka dan relatif cukup lebar, berkisar 6 hingga 12 meter. Koridor merupakan pembentuk kualitas ruang dan arsitektural dari ruang yang melingkupinya, serta dapat digunakan oleh publik dan juga memberikan kesempatan timbulnya bermacam-macam kegiatan (Kristiawan, 1998). Dengan demikian, Eco- Riverwalk Village merupakan konsep yang bertujuan untuk membangun area yang ramah lingkungan dengan mengoptimalkan ekologi kawasan tepi sungai (i.e riverfronts) tetap dengan mempertahankan nilai estetika dan rekreasi dengan konsep riverwalk. Konsep riverwalk yang ramah lingkungan menjadi daya tarik pengunjung dikawasan riverfronts Mlatiharjo dengan pengembangan kawasan RTH aktif di kawasan riverfronts.

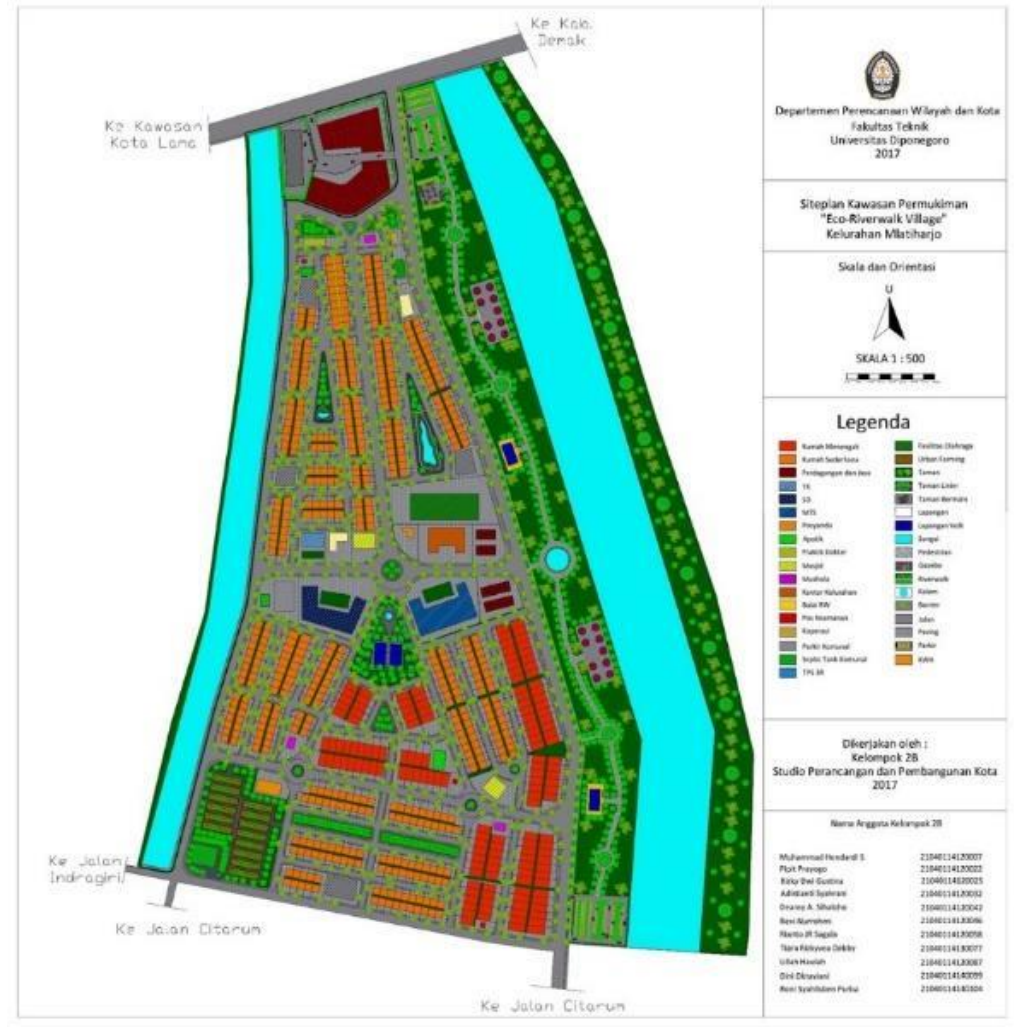

Gambar 2. Siteplan Kawasan Perancangan Mikro (Analisis Penulis, 2017)

Pengembangan kawasan tepi sungai BKT dengan konsep yang ramah lingkungan dan memiliki fasilitas yang dekat untuk dijangkau (i.e maksimal $200 \mathrm{~m}$ ) menjadi daya 6arik masyarakat agar nyaman dalam menyusuri sungai dengan berjalan kaki (by walking). Konsep inipun menjadi pemecahan masalah kawasan dan dapat mengoptimalkan potensi. Dengan pengembangan kawasan tepi sungai (i.e diterapkan setelah sempadan sungai selebar minimal 5 
meter) menjadi RTH aktif dan berada dekat dengan fasilitas kelurahan akan meningkatkan nilai kenyaman dan kekompakkan (i.e compact).

Tabel 1. Permasalahan dan Implementasi Konsep Pada Kawasan Perancangan (Analisis Penulis, 2017)

\begin{tabular}{|c|c|c|}
\hline Permasalahan & Konsep & Implementasi Konsep \\
\hline $\begin{array}{l}\text { - Land } \\
\text { Subsidence } \\
\text { - Permukiman } \\
\text { Kumuh } \\
\text { (Slums) } \\
\text { - Banjir } \\
\text { - Buruknya } \\
\text { Lingkungan } \\
\text { Hidup }\end{array}$ & $\begin{array}{l}\text { - Penerapan RTH Privat di setiap } \\
\text { rumah. } \\
\text { Perumahan yang berada di kawasan } \\
\text { mikro harus memnuhi } 30 \% \text {. Sehingga } \\
\text { building coverage maksimal adalah } \\
70 \% \text {. Penerapan RTH diterapkan } \\
\text { pada halaman depan atau belakang } \\
\text { ruah. }\end{array}$ & \\
\hline $\begin{array}{l}\text { - Land } \\
\text { Subsidence } \\
\text { - Squatters di } \\
\text { Bantaran } \\
\text { Sungai } \\
\text { - Sedimentasi } \\
\text { - Banjir }\end{array}$ & $\begin{array}{l}\text { - Taman Linier } \\
\text { Pada Konsep Eco-Riverwalk Village, } \\
\text { banyak diterapkan taman hujan/rain } \\
\text { garden yang fufngsinya sebagai } \\
\text { daerah resapan air. Hal ini } \\
\text { diwujudkan kedalam RTH aktif } \\
\text { berupa taman linier di sepanjang } \\
\text { BKT. }\end{array}$ & \\
\hline $\begin{array}{l}\text { - Buruknya } \\
\text { Lingkungan } \\
\text { Hidup } \\
\text { - Land } \\
\text { Subsidence }\end{array}$ & $\begin{array}{l}\text { - Penerapan Urban Farming } \\
\text { Keberadaan Urban Farming selain } \\
\text { urgensi utamanya sebagai upaya } \\
\text { ketahanan pangan kota juga } \\
\text { digunakan untuk meningkatkan } \\
\text { kualitas lingkungan hidup dengan } \\
\text { penghijauan berupa perkebunan dan } \\
\text { dibangun secara komunal agar dapat } \\
\text { berfungsi sebagai daerah resapan air } \\
\text { sebagai respon permasalahan land } \\
\text { subsidence }\end{array}$ & \\
\hline $\begin{array}{l}- \text { Land } \\
\text { Subsidence }\end{array}$ & $\begin{array}{l}\text { - Efisiensi Pengolahan Limbah } \\
\text { dan Pemanfaatan Energi } \\
\text { RWH dibangun sebagai upaya } \\
\text { pengurangan penggunaan air tanah. } \\
\text { Penggunaan air tanah yang } \\
\text { berlebihan dapat menyebabkan land } \\
\text { subsidendce }\end{array}$ & \\
\hline
\end{tabular}

\section{Konsep Manajemen Pengelolaan dan Pembiayaan Kawasan Mikro}

Kondisi eksisting lokasi perancangan berupa permukiman padat dan kawasan perdagangan jasa di bantaran Sungai Banjir Kanal Timur. Lokasi perancangan di Kelurahan Mlatiharjo direncanakan merupakan perencanaan pembangunan yang memiliki fungsi utama berupa permukiman. Tahapan pembangunan kawasan dibagi menjadi dalam tiga tahap yaitu pra-konstruksi, konstruksi dan pasca-konstruksi. Tahap pra konstruksi berupa proses kajian, perizinan, dan pembebasan lahan. Pemerintah berperan sebagai aktor utama dalam proses prakonstruksi seperti negosiasi, perizinan dan sosialisasi. Tahap konstruksi adalah berupa pembangunan fisik seperti fisik hunian dan infrastruktur penunjang. Sedang tahap pascakonstruksi adalah pengoperasian dan atau manajemen pengelolaan atau pemelihaaraan kawasan yang telah dibangun. Tahapan pembangunan kawasan juga dilakukan secara bertahap pada 
setiap zona. Mulai dari kawasan riverwalk, zona 1, zona 2, hingga zona 3. Berikut ini peta pembagian zona pada kawasan perancangan.

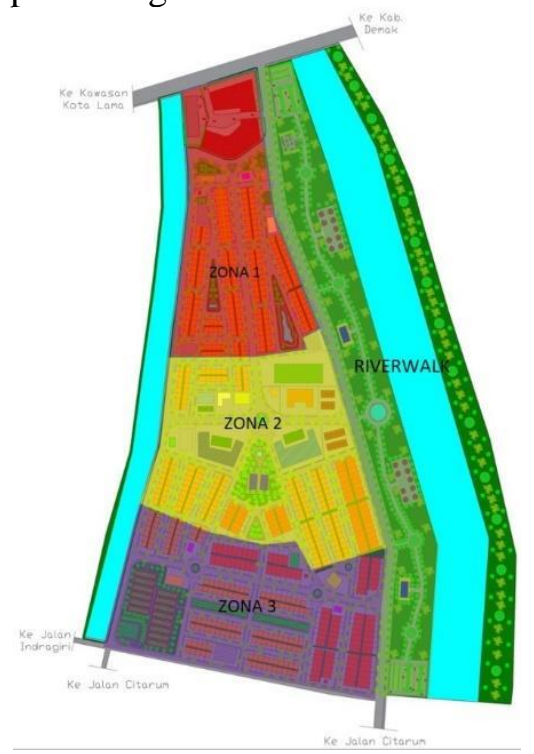

Gambar 3. Siteplan Kawasan Perancangan Mikro (Analisis Penulis, 2017 )

Lokasi perancangan yang dibagi menjadi 3 zona pembangunan dimulai dari pembangunan kawasan riverwalk, perdagangan jasa lalu kawasan hunian. Jenis kerjasama yang dilakukan dalam pembangunan kawasan permukiman Mlatiharjo adalah PPP (Public Private Partnership), sedang bentuk kerjasama yang dilakukan adalah BOT (Built Operate Transfer), swastanisasi dan pengelolaan oleh pemerintah.

Justifikasi Konsep Pengelolaan

1. Pemerintah

Dalam pembangunan kawasan pemerintah melakukan pengelolaan aset baik dari tahap pra hingga pasca konstruksi. Peran pemerintah dalam pengelolaan ini sepenuhnya dilakukan mandiri tanpa ada kerjasama pengelolaan dengan swasta. Pembangunan yang dilakukan berupa pembangunan infrastruktur dasar dan normalisasi sungai BKT (Banjir Kanal Timur).

Tabel 2. Peran Pemerintahan dalam Pengelolaan Konstruksi (Analisis Penulis, 2017)

\begin{tabular}{|l|l|l|}
\hline \multicolumn{1}{|c|}{ Pra-Konstruksi } & \multicolumn{1}{|c|}{ Konstruksi } & \multicolumn{1}{c|}{ Pasca Konstruksi } \\
\hline Pada tahap pra- & Pada tahap konstruksi pemerintah & Peran Pemerintah pada tahap \\
konstruksi & melakukan pembangunan berupa: & pasca konstruksi adalah: \\
pemerintah berperan & - Melakukan normalisasi dan & - Melakukan Operate dan \\
dalaam hal: & pembangunan riverwalk & Maintenance sarana prasana \\
- Melakukan proses & - Memenuhi infrastruktur dasar & dasar: MTSN, SD, Kantor \\
negosiasi dengan & kawasan hunian seperti: MTsN, & Kelurahan, Posyandu \\
masyarakat & SD, kantor kelurahan, balai RW, & - Melakukan Operate dan \\
mengenai & masjid dan posyandu & maintenance riverwalk \\
redevelopment & - Membangun jaringan listrik dan & melalui instansi berwenang \\
kawasan & air bersih & (Dinas Pertamanan, dinas \\
Melakukan proses & - Melakukan pembangunan & kebersihan) \\
perizinan & Koperasi untuk menunjang & - Melakukan operate dan \\
pembangunan & kemandirian ekonomi kawasan & maintenance jaringan listrik \\
kawasan & - Melakukan pembangunan RWH & dan air bersih, serta \\
Analisis AMDAL & (Raint Water Harvesting) & melakukan penarikan \\
Melakukan & sebagai pemecahan masalah & retribusi \\
sosialisasi. & penggunaan air tanah untuk & - Pembangunan infrastruktur \\
& mengurangi land subsidance & seperti Balai RW, Masjid \\
& & koperasi dan RWH pada \\
& & tahap pra konstruksi \\
& & dilakukan oleh masyarakat. \\
\hline
\end{tabular}




\section{Swastanisasi}

Kerjasama dalam swastanisasi dilakukan oleh swasta dan pemerintah. Peran swasta lebih terlihat dalam kerjasama ini pemerintah banyak berperan pada proses pra konstruksi seperti pembebasan lahan dan proses perizinan. Sedangkan pengelolaan lebih lanjut banyak di lakukan oleh swasta hingga pada tahap pasca konstruksi.

Tabel 3. Peran Swasta dalam Pengelolaan Konstruksi (Analisis Penulis, 2017)

\begin{tabular}{|l|l|l|}
\hline \multicolumn{1}{|c|}{ Pra-Konstruksi } & \multicolumn{1}{|c|}{ Konstruksi } & \multicolumn{1}{c|}{ Pasca Konstruksi } \\
\hline - Pemerintah melakukan & - Swasta melakukan & - Pada tahap pasca konstruksi \\
proses & pembangunan Hunian & Swasta melakukan Operate \\
pembebasanlahan, & menengah, hunian sederhana, & dan Maintenance pada \\
pematangan lahan, & kawasan perdagangan jasa, & kawasan perdagangan \\
perizinan, AMDAL dan & apotik, klinik dan & jasa,hunian menengah, hunian \\
sosialisasi. & diswastanisasikan artinya & sederhana, apotek dan klinik. \\
- Melakukan & dalam hal pembangunan dan & Aset tersebut merupakan hak \\
kerjasamaantara swasta & hak milik aset. & milik swasta baik lahan \\
dengan pemerintah & - Selain pembangunan yang & ataupun bangunan. Profit dari \\
dalam menentukan & menghasilkan profit swasta & pengoperasian asset tersebut \\
kontrak kerjasama & juga melakukan pembangunan & juga merupakan hak swasta \\
& berupa penunjang kawasan & sepenuhnya. \\
& hunian seperti Taman RW, & - Aset berupa penunjang \\
& Septick Tank komunal, pos & kawasan hunian berupaTaman \\
& keamanan dan mushola. & RW, septick tank komunal, \\
& \multicolumn{2}{|c}{ pos keamanan dan mushola } \\
& \multicolumn{2}{c}{ akan di kelola oleh masyarakat } \\
& \multicolumn{2}{c}{ setelah proses pembangunan } \\
\end{tabular}

\section{BOT (Built Operate Transfer)}

Jenis pembangunan melalui kerjasama BOT ini dilakukan kerjasama swasta dan pemerintah dimana setelah jangka waktu yang ditentukan aset yang dibangun swasta akan di transfer ke pemerintah. Sistem BOT ini setiap asetnya berbeda jangka waktu transfernya disesuakian dengan fungsinya.

Tabel 4. Peran Swasta dan Pemerintah dalam Kerjasama BOT (Analisis Penulis, 2017)

\begin{tabular}{|c|c|c|}
\hline Pra-Konstruksi & Konstruksi & Pasca Konstruksi \\
\hline $\begin{array}{l}\text { - Pemerintah } \\
\text { melakukan proses } \\
\text { pembebasan } \\
\text { lahan, perizinan, } \\
\text { AMDAL dan } \\
\text { sosialisasi } \\
\text { - Melakukan } \\
\text { kerjasama antara } \\
\text { swasta dengan } \\
\text { pemerintah dalam } \\
\text { menentukan } \\
\text { kontrak baik } \\
\text { kerjasama baik } \\
\text { pembangunan } \\
\text { atau jangka } \\
\text { waktu BOT. }\end{array}$ & $\begin{array}{l}\text { Pada tahap kosntruksi } \\
\text { dilakukan pembangunan } \\
\text { secara bertahap mulai dari } \\
\text { zona 1- zona } 3 \text { oleh swasta } \\
\text { yaitu melakukan } \\
\text { pembangunan: Jalan } \\
\text { Lokal, Jalan Lingkungan, } \\
\text { Parkir Komunal dan } \\
\text { Gedung Olahraga. }\end{array}$ & $\begin{array}{l}\text { - Swasta melakukan Operate dan } \\
\text { maintenance jalan selama } 5 \text { tahun setelah } \\
\text { pembangunan selesai pada setiap tahap } \\
\text { setelah itu dilakukan transfer kepada } \\
\text { pemerintah. } \\
\text { - Pemerintah melakukan operate dan } \\
\text { maintenance jalan setelah proses } \\
\text { transfer. } \\
\text { - Swasta melakukan operate dan } \\
\text { maintenance parkir komunal dan gedung } \\
\text { olahraga selama } 15 \text { tahun, setelahnya } \\
\text { dilakukan transfer kepada pemerintah. } \\
\text { - Profit dari parkir komunal dan gedung } \\
\text { olahraga selama } 15 \text { tahun setelah } \\
\text { pembangunan merupakan benefit swasta } \\
\text { setelah proses transfer maka menjadi } \\
\text { benefit pemerintah. }\end{array}$ \\
\hline
\end{tabular}




\section{Pembiayaan}

Pembiayaan yang dikaji dilihat berdasarkan bentuk pengelolaan yang dilakukan, meliputi pemerintah murni, swasta murni, dan BOT. Adapun segi pembiayaan mempertimbangkan sisi finansial dan sisi sosial. Kemudian besaran benefit (keuntungan) dan cost (pengeluaran) perlu diketahui agar dapat dilakukan analisis manajemen pembiayaannya. Analisis tersebut penting dilakukan agar dapat diketahui kelayakan dari proyek pembangunan tersebut. Instrumen yang digunakan di antaranya adalah Net Present Value (NPV), Benefit/Cost Racio (BCR), dan Payback Period. Payback Period merupakan jangka waktu kembalinya investasi yang telah dikeluarkan, melalui keuntungan yang diperoleh dari suatu proyek yang telah direncanakan (Choliq \& Wirasasita, 2004). Disamping itu, analisis finansial perlu memperhatikan cash-flow yaitu perbandingan antara hasil penerimaan atau penjualan kotor (gross-sales) dengan jumlah biaya-biaya (total cost) yang dinyatakan dalam nilai sekarang untuk mengetahui kriteria kelayakan atau keuntungan suatu proyek. Berikut hasil perhitungan pembiayaan untuk pembangunan pada lokasi perancangan

Tabel 5. Perhitungan Pembiayaan Pembangunan (Analisis Penulis, 2017)

Finansial pemerintah

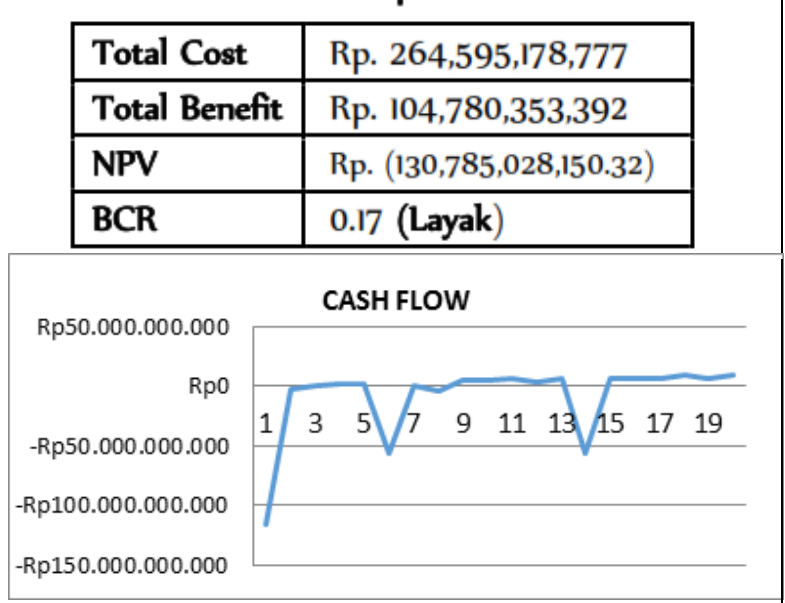

Aliran kas finansial pemerintah dalam pembangunan bersifat fluktuati dimana kas menurun setiap awal tahap pembangunan dan mulai stabil tahun ke 15

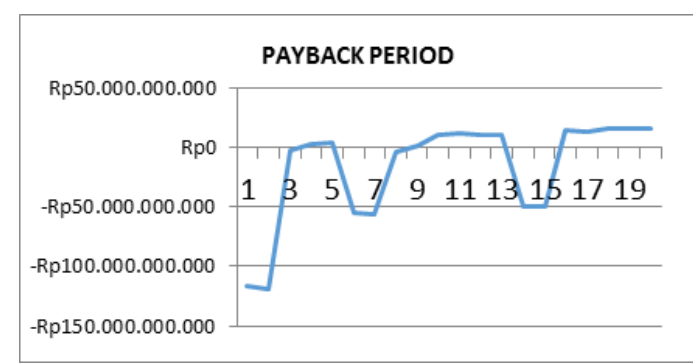

Investasi kembali pada tahun ke 4 namun turun lagi pada tahun ke 7, dan terulang di tahun ke 13. investasi diperkirakan dapat kembali secara stabil pada tahun ke 16

Finansial Swasta

\begin{tabular}{|l|l|}
\hline Total Cost & Rp 3.008.000.000 \\
\hline Total Benefit & Rp 17.055.120.000 \\
\hline NPV (PVB-PVC) & Rp 8.500.383.430,3 \\
\hline BCR (PVB/PVC) & 7.23 (Lavak) \\
\hline
\end{tabular}

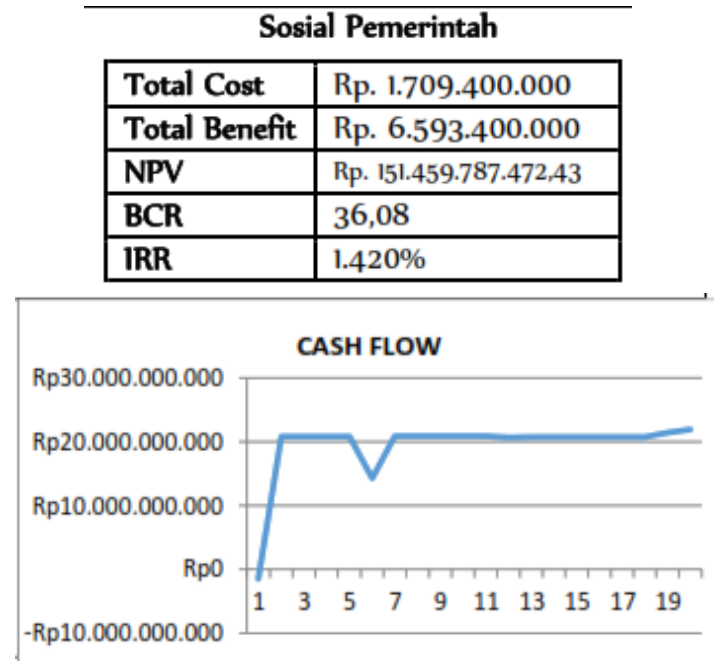

Aliran kas social ekonomi pemerintah cenderung stabil, hanya mengalami sedikit penurunan pada tahun ke 7 namun kemudian naik dan kembali stabil

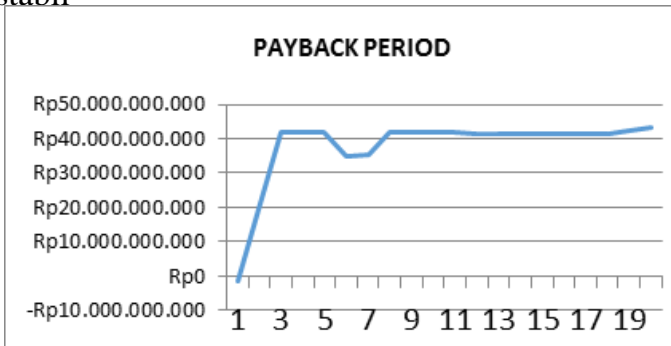

Investasi social ekonomi sudah dapat kembali dari tahun ke 2 hingga tahun seterusnya hingga tahun ke 20

Sosial Ekonomi Swasta

\begin{tabular}{|l|l}
\hline Total Cost & 96.278 .216 .265 \\
\hline Total Benefit & 362.988 .080 .195 \\
\hline $\begin{array}{l}\text { NPV(PVB- } \\
\text { PVC) }\end{array}$ & 23.536 .112 .891 \\
\hline BCR(PVB/PVC) & 1,52 \\
\hline IRR & $26,1 \%$ \\
\hline
\end{tabular}




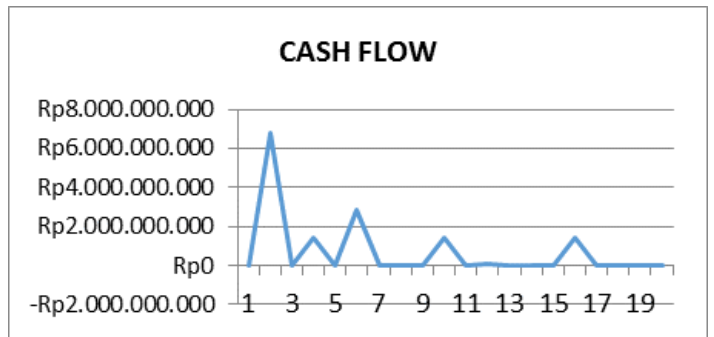

Aliran kas naik turum namun sampai dibawah angka 0 artinya tidak sampai mengalami deficit tapi tidak juga mengalami kenaikan vang signifikan

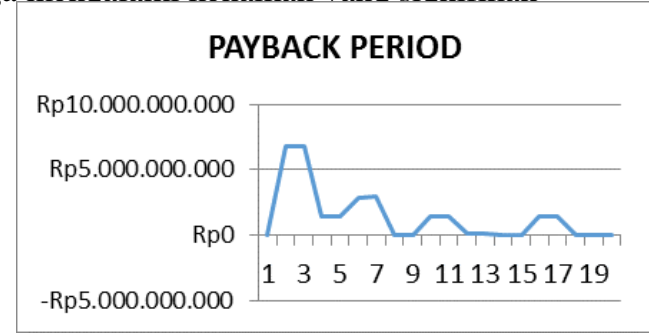

Investasi swasta sudah dapat kembali pada tahun ke 2 namun dana nya terus menurun hingga tahun ke 20

\begin{tabular}{|l|l|}
\multicolumn{2}{c}{ Finansial BOT } \\
\begin{tabular}{|l|l|}
\hline Total Cost & 9.558 .693 .000 \\
\hline Total Benefit & 18.958 .100 .000 \\
\hline NPV (PVB-PVC) & $345.148 .528,97$ \\
\hline BCR(PVB-PVC) & $1,09($ Layak $)$ \\
\hline IRR & $13.6 \%$ \\
\hline
\end{tabular}
\end{tabular}

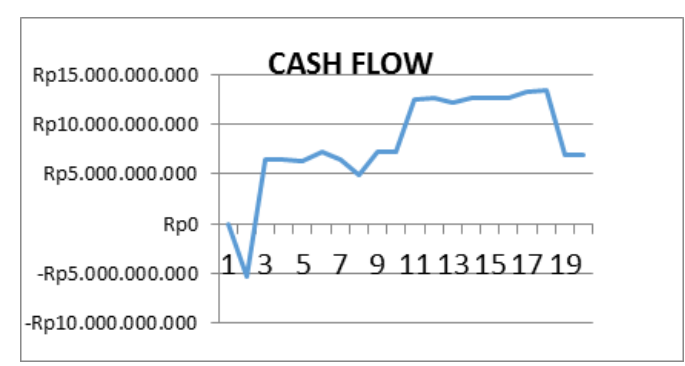

Aliran dana pada pada kerjasama BOT terus naik mulai tahun ke 3 namun pada tahun ke 19 mengalami penurunan

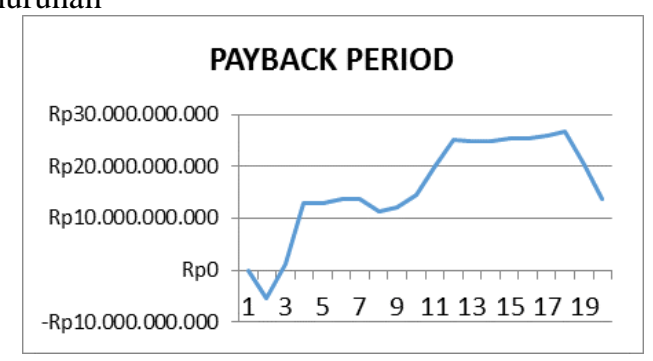

Investasi BOT sudah kembali pada tahun ke 4. Mengalami kenaikan pada tahun ke 9-12 lalu stabil hingga tahun ke 20

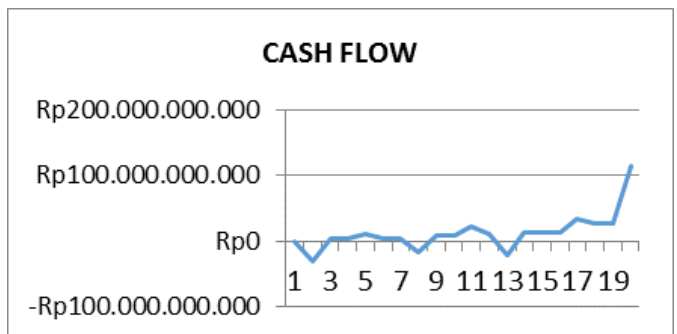

Aliran kas social swasta fluktuatif dan mulai naik pada tahun ke 14

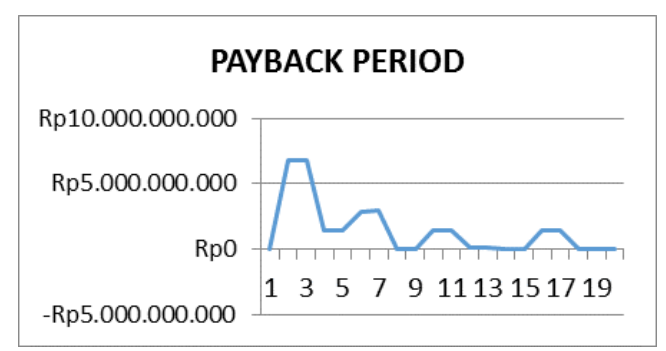

Investasi social ekonomi pada swasta dapat kembali pada tahun ke 16 dan mengalami kenaikan pesat pada tahun ke 19

Sosial BOT

\begin{tabular}{|l|l}
\hline Total Cost & 9.370 .606 .510 \\
\hline Total Benefit & 172.176 .000 .000 \\
\hline NPV(PVB-PVC) & $36.204 .618 .231,28$ \\
\hline BCR(PVB/PVC) & $7,30($ Layak) \\
\hline IRR & $123,9 \%$ \\
\hline
\end{tabular}

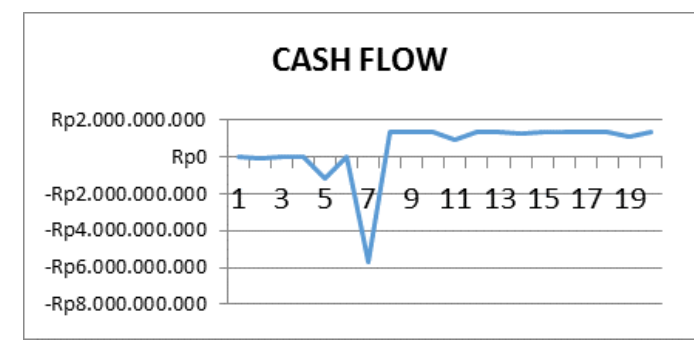

Aliran dana social ekonomi mengalami penurunan di tahun ke 7 , dan kembali naik pada tahun ke 8 hingga seterusnya

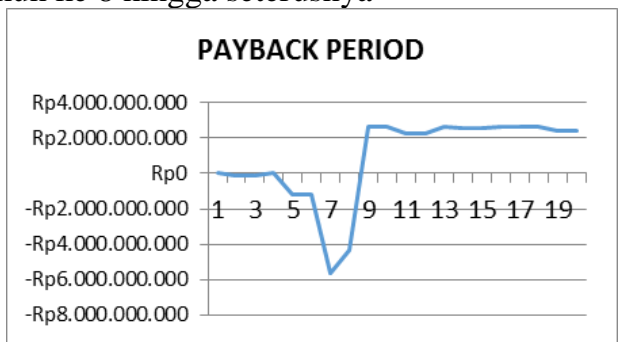

Investasi social ekonomi juga mengalami penurunan di tahun ke 7 namun naik kembali di tahun ke 9 kemudian mengalir stabil hingga tahun ke 20

\section{Kesimpulan}

Konsep Eco-Riverwalk Village adalah konsep yang mengedepankan aspek ekologis dalam mengembangkan kawasan riverfront sungai BKT. Dalam implementasikannya, dibangun taman linier yang bertujuan memperbaiki hubungan manusia dan lingkungannya. Hal ini dinilai dari desain taman yang ramah lingkungan. Taman linier yang menjadi identitas baru lokasi perancangan menjadi daya tarik lokasi perancangan yang merupakan kawsan permukiman. Permukiman yang awalnya kumuh, dengan pendekatan yang mengedepankan aspek ekologi 
dapat menciptakan kawasan ideal dengan penerapan standar permukiman di dalamnya. Pada tahap manajemen pengelolaan, dibagi menajdi tiga tahap, yaitu tahap pra konstruksi, konstruksi dan pasca konstruksi. Adapun stakeholder yang terlibat yaitu pemerintah dan swasta dengan bentuk kerjasama Built-Operate-Transfer (BOT). Berdasarkan pembiayaan pembangunan, kelayakan pembangunan konsep desain ini dinilai layak dan dapat memberi keuntungan sosial yang tinggi bagi publik.

\section{Referensi}

Choliq, A., \& Wirasasita, R. (2004). Evaluasi Proyek, Suatu Pengantar (Cetakan Ke). Bandung.

Community and Economic Development Department. 2005. Thea Foss Waterway Design and Development Plan. Washington

Haeckel, E. (1866). Generelle Morphologie der Organismen : allgemeine Grundzüge der organischen Formen-Wissenschaft, mechanisch begründet durch die von Charles Darwin reformirte Descendenz-Theorie. Berlin.

Hussein, Hazzrena. 2003. Urban Recreational Riverfronts: Successful Revitalisation Elements. International Navigation Association. Guidelines for Sustainable Inland Waterways and Navigation. Belgium.

Iswandi, R. Marsuki. 2015. Perencanaan dan Pengembangan Kota Pesisir Berwawasan Lingkungan. Unhalu Press: Kendari.

Kristiawan, B. . (1998). Koridor Utama Sebagai Generator Kota Lama Semarang. Vasthu, VI(02), 53-66.

Marfai, M. A. (2004). Tidal Flood Hazard Assessment : Modeling in Raster GIS, Case in Western Part of Semarang Coastal Area. International Journal of Geography, 36(1), 25-38.

Novendra, Tommy. 2014. Studi Konsep Ekologis Area Permukiman Kawasan Pariwisata Pantai. Dalam http://e-journal.uajy.ac.id/6601/1/JURNAL\%20MTA01930.pdf. Diunduh pada tanggal 15 Februari 2017.

Otto, Betsy, Kathleen McCormick dan Michael Leccese. 2004. Ecological Riverfront Design: Restoring Rivers, Connecting Communities. Washington DC: American Planning Association.

Prabowo, Agus. 2011. Neighborhood Unit. Dalam http://membacaruang.com/neighborhood-unit/. Diakses tanggal 25 Februari.

Peraturan Menteri Pekerjaan Umum dan Perumahan Rakyat Republik Indonesia Nomor 02/PRT/M/2016 Tentang Peningkatan Kualitas Terhadap Perumahan Kumuh dan Permukiman Kumuh.

Peraturan Menteri Pekerjaan Umum Dan Perumahan Rakyat Republik Indonesia Nomor 28/PRT/M/2015 Tentang Penetapan Sempadan Sungai dan Garis Sempadan Danau.

Peraturan Pemerintah Republik Indonesia Nomor 14 Tahun 2016 Tentang Penyelenggaraan Perumahan Dan Kawasan Permukiman.

Sastrawati, Isfa. 2003. Prinsip Perancangan kawasan Tepi Air. Jurnal Perencanaan Wilayah dan Kota, 14 (3): 95 - 117. http://eng.unhas.ac.id/pwk/files/5842e12a9d7df.pdf. Diunduh pada tanggal 15 Februari 2017.

Safrilia, Adisti. 2013. Perancangan Resort dengan Penerapan Prinsip Ekologi Di Pulau Menjangan Kecil Karimun jawa. Dalam http://arsitektur.ub.ac.id/wpcontent/uploads/2013/10/JURNALILMIAH12. pdf. Diakses pada 22 Februari 2017.

SNI-03-1733-2004 Tata Cara Perencanaan Lingkungan Permukiman Di Perkotaan.

Suripin. (2004). Sistem Drainase Perkotaan yang Berkelanjutan. Yogyakarta: Andi.

Syarapuddin, Herry Santosa. 2016. Pendekatan Arsitektur Ekologi pada Perancangan Kawasan Wisata Danau Lebo Kabupaten Sumbawa Barat. Dalam http://arsitektur.studentjournal.ub.ac.id/ index.php/jma/article/view/191. Diunduh pada 22 Februari 2017.

Tangkuman, Dwi Juwita dan Tandolaba Linda. 2011. Arsitektur Tepi Air (Waterfront Architecture). Media Matrasain, Volume 8, Nomor 2. file:///C:/Users/revi/Downloads/325-661-1-PB.pdf. Diunduh pada tanggal 25 Februari 2017.

Todd, John, Diane Gayer dan Sacha Lozano. 2007. The Burlington Waterfront: an Ecological Design Approach. Dalam http://www.uvm.edu/ dgayer/dg\%20website/2007 Ecological DesignWaterfront.ppt. Diunduh pada tanggal 15 Februari 2017.

Undang-undang Nomor 1 Tahun 2011 Tentang Perumahan dan Kawasan Permukiman.

Yang, Y. C., \& Xu, T. C. 2012. Assessing a Riverfront Rehabilitation Project Using The Comprehensive Index of Public Accesibility. Dalam http://doi.org/10.1016/j.ecoleng.2011.12.008. Diunduh pada tanggal 25 Februari 2017. 